\title{
Comparison of Vitamin D Levels between Genders, Age Groups and Geographical Locations in a Tertiary Care Hospital of Dakshina Kannada: A Cross Sectional Study
}

\author{
Mahalaxmi S Petimani ${ }^{1}$, Adarsh Aithal ${ }^{2}$, Prabhakar Adake ${ }^{3 *}$ \\ ${ }^{1}$ Assistant Professor of Biochemistry, Yenepoya Medical College, Yenepoya (Deemed to be University), Deralakatte, Mangalore-575018, Karnataka, \\ India \\ ${ }^{2}$ Third Year Medical Scholar, Yenepoya Medical College, Yenepoya (Deemed to be University), Deralakatte, Mangalore-575018, Karnataka, India \\ ${ }^{3}$ Associate Professor of Pharmacology, Yenepoya Medical College, Yenepoya (Deemed to be University), Deralakatte, Mangalore-575018, Karnataka, \\ India
}

DOI: $10.36348 /$ sijb.2020.v03i02.003

| Received: 04.02.2020 | Accepted: 11.02.2020 | Published: 15.02.2020

*Corresponding author: Dr. Prabhakar Adake

Email: dradake82@gmail.com

\section{Abstract}

Objectives: To compare the vitamin D levels between genders, age groups and geographical locations in a tertiary care hospital of Dakshina Kannada. Materials and Methods: A total of $208(\mathrm{n}=208)$ reports containing vitamin D levels were collected from Central laboratory, which were reported between January 2015 to December 2015. The values are tabulated in Microsoft excel sheet. Student' $t$ ' test was applied to compare the vitamin D levels between males and females. Whereas, ANOVA was applied for comparing vitamin D levels between different age groups and geographical locations. Results: Out of 208 vitamin D reports, $86(41.3 \%)$ reports were from male and $122(58.7 \%)$ from females. The mean values of vitamin D in males and females were 32.9 \pm 14.7 and 31.1 \pm 21.4 respectively. Even though females have low levels of vitamin D when compared to males but statistically it was not significant ( $\mathrm{p}=0.512)$. The mean value of vitamin D from different geographical locations ranged from $20.9 \mathrm{ng} / \mathrm{ml}$ (from Ankola) to $78.6 \mathrm{ng} / \mathrm{ml}$ (from Dharwad) and $27.3 \pm 11.1$ being noted from Dakshina Kannada. The intergroup comparison of vitamin D levels of individuals from different locations didn't show any statistical significance ( $f=1.33 \& p=0.191$ ). Similarly, there is no statistical significant difference in the vitamin D levels of different age groups. Conclusion: The present study concludes that there is no statistical significant difference in the vitamin D levels of males with females and also no significant difference was found in the vitamin D levels of different age groups and different geographical locations.

Keywords: Vitamin D, Geographical location, ANOVA.

Copyright @ 2020: This is an open-access article distributed under the terms of the Creative Commons Attribution license which permits unrestricted use, distribution, and reproduction in any medium for non-commercial use (NonCommercial, or CC-BY-NC) provided the original author and source are credited.

\section{INTRODUCTION}

Vitamin D is a fat soluble hormone that plays
essential role in calcium homeostasis and
mineralization of bones [1]. Vitamin D helps in
absorption of calcium from the gut. Calcium is required
for repair of aging bones or formation of bone.
Decreased calcium levels can lead to condition known
as osteoporosis due to decreased bone density. Source
of vitamin D can be exogenous or endogenous.
Endogenous vitamin D is synthesized due to exposure
to ultraviolet lights and exogenous is supplemented by
dietary sources [2, 3]. Vitamins D3 (Cholecalciferol)
and D2 (Ergocalciferol) are metabolized in an identical
manner in the liver to 25-hydroxyvitamin D [4]. Further
25-hydroxyvitamin D is converted to 1,25-
hydroxyvitamin D (active vitamin D) in the kidney by the enzyme $1 \alpha$-hydroxylase [5]. 25-hydroxyvitamin D has approximately 10-15 days of half-life, which makes it ideal for the measurement of vitamin $D$ [6]. Biochemically, levels $<20 \mathrm{ng} / \mathrm{mL}$ are defined as 'deficiency' and levels of 25(OH)vitamin D >30 ng/mL are considered as 'normal'. Levels between 20 and 30 $\mathrm{ng} / \mathrm{mL}$ are defined as 'insufficiency'. The prevalence of vitamin D deficiency in India ranges from 80\%-90\% [79].

Many studies have revealed that decreased vitamin D levels can cause negative bone mineralization leading to rickets in children and osteomalacia in adults [10]. Moreover, vitamin D insufficiency can be associated with other diseases like chronic kidney disease (CKD) which in turn leads to secondary hyperparathyroidism leading to loss of bone 
density and higher incidence fractures. Hypovitaminosis D is also associated with cancers, autoimmune diseases, multiple sclerosis and asthma [11].

Hence, this present research topic is selected to evaluate which gender and age group of patients belonging to different geographical location has hypovitaminosis D.

\section{OBJECTIVES}

To compare the vitamin D levels between genders, age groups and geographical locations in a tertiary care hospital of Dakshina Kannada

\section{METHODOLOGY}

The present cross-sectional study was conducted in Department of Biochemistry, Yenepoya Medical College, Mangalore, Karnataka after Institutional Ethics Committee approval. The study duration was five months starting from August 2019 to December 2019.

The sample size was calculated based on the previous study done by Randip Chowdhary [14].In this study the prevalence rate of Vitamin D deficiency found to be $34.5 \%$. ie $p=0.345$. Considering standard normal variate with $5 \%$ level of significance and $10 \%$ sample size missing response, the final sample size was found to be 200. So in this study we collected 208 $(n=208)$ blood reports containing vitamin D levels of patients (reported between January 2015 to December 2015) from Central Laboratory of Yenepoya Medical College Hospital, Deralakatte, Mangalore. Patient name was anonymized and only gender, age, geographic area and vitamin $\mathrm{D}$ values were entered in the excel sheet. Following table shows reference values of vitamin D level in central laboratory, Yenepoya Medical College Hospital, Mangalore.

\begin{tabular}{|c|c|c|}
\hline Variables & Source & Vitamin D Reference Values in our setting \\
\hline Socio demographic data & Vitamin D levels & Sufficiency: $30-100 \mathrm{ng} / \mathrm{ml}$ \\
(Age/Gender/ & & Insufficiency: $20-30 \mathrm{ng} / \mathrm{ml}$ \\
Geographical location) & & Deficiency: $<20 \mathrm{ng} / \mathrm{ml}$ \\
& & Toxicity: $>100 \mathrm{ng} / \mathrm{ml}$ \\
\hline
\end{tabular}

\section{STATISTICAL ANALYSIS}

Data entry and analysis were done using IBM SPSS 23 software. Continuous variables are expressed as mean \pm sd and categorical variables as frequency and percentages. Student ' $t$ ' test was applied to compare the vitamin D levels between males and females. Whereas, ANOVA was applied for comparing vitamin D levels between different age groups and geographical locations.

\section{RESULTS}

Table- 1 shows the details of study participants. Out of 208 vitamin D reports, 86 (41.3\%) reports were from male and $122(58.7 \%)$ from females. The mean values of vitamin $D$ in males and females were $32.9 \pm 14.7$ and $31.1 \pm 21.4$ respectively. Even though females have low levels of vitamin D when compared to males but statistically it was not significant $(\mathrm{p}=0.512)$. Least level of vitamin $\mathrm{D}$ was observed in the age group of $50-60$ years i.e. $28.4 \pm 21.1 \mathrm{ng} / \mathrm{dl}$ and highest in 60-70 years of age i.e. 36.5 23.9 (Table-2). However, they are statistically insignificant $(p=0.34$.) The mean value of vitamin $\mathrm{D}$ from different geographical locations ranged from $20.9 \mathrm{ng} / \mathrm{ml}$ (from Ankola) to $78.6 \mathrm{ng} / \mathrm{ml}$ (from Dharwad) and 27.3 \pm 11.1 being noted from Dakshina Kannada (Table-3). The intergroup comparison of vitamin D levels of individuals from different locations didn't show any statistical significance ( $\mathrm{f}=1.33 \& \mathrm{p}=0.191$ ). Our study also showed that around $41.8 \%$ of participants have sufficient vitamin D levels, $31.7 \%$ have insufficiency, $25 \%$ have deficiency and $1.4 \%$ of participants have toxic vitamin D levels (Figure-1).

Table-1: Table showing the details of study participants

\begin{tabular}{|l|l|l|l|l|}
\hline Gender & Number & Percentage & Vitamin D level (mean \pm sd) & Student t test p value \\
\hline Male & 86 & 41.3 & $32.9 \pm 14.7$ & $\mathrm{t}$ test $=0.657$ \\
\cline { 1 - 4 } Female & 122 & 58.7 & $31.1 \pm 21.4$ & 0.512 \\
\hline Total & 208 & 100 & & \\
\hline
\end{tabular}

Table-2: Table showing age wise distribution of study participants

\begin{tabular}{|c|c|c|c|c|}
\hline Age & Number & Percentage & Vitamin D level (mean \pm sd) & $f$ and $p$ value \\
\hline Less than 10 Years & 1 & .5 & 33.2 & \multirow{7}{*}{$\begin{array}{l}f=1.12 \\
p=0.34\end{array}$} \\
\hline 10-20 Years & 7 & 3.4 & $31.0 \pm 11.3$ & \\
\hline 20-30 Years & 33 & 15.9 & $33.5 \pm 15.3$ & \\
\hline 30-40 Years & 40 & 19.2 & $29.1 \pm 12.2$ & \\
\hline 40-50 Years & 35 & 16.8 & $33.6 \pm 19.7$ & \\
\hline 50-60 Years & 46 & 22.1 & $28.4 \pm 21.1$ & \\
\hline $60-70$ Years & 43 & 20.7 & $36.5 \pm 23.9$ & \\
\hline
\end{tabular}




\begin{tabular}{|l|l|l|l|l|}
\hline More than 70 Years & 3 & 1.4 & $15.0 \pm 7.7$ & \\
\hline Total & 208 & 100.0 & & \\
\hline
\end{tabular}

Table-3: Table showing Vitamin-D levels among all the different geographical location

\begin{tabular}{|l|l|l|l|l|}
\hline Location & Number & Percentage & Vitamin D level (mean \pm sd) & f and p value \\
\hline Ankola & 1 & .5 & 20.9 & $\mathrm{f}=1.33$ \\
$\mathrm{p}=0.191$ \\
\hline Chikamangalore & 7 & 3.4 & $31.9 \pm 14.3$ & \\
\hline Dakshina Kannada & 72 & 34.6 & $27.3 \pm 11.1$ \\
\hline Davangere & 43 & 20.7 & $30.5 \pm 13.9$ \\
\hline Dharwad & 1 & .5 & 78.6 \\
\hline Haveri & 7 & 3.4 & $43.2 \pm 33.2$ \\
\hline Kannur & 40 & 19.2 & $36.9 \pm 28.7$ \\
\hline Kasargod & 17 & 8.2 & $33.0 \pm 17.6$ \\
\hline Karwar & 1 & .5 & 44.2 \\
\hline Kundapura & 1 & .5 & 40.9 \\
\hline Raichur & 1 & .5 & 35.9 & \\
\hline Shimoga & 12 & 5.8 & $33.3 \pm 22.7$ \\
\hline Sirsi & 1 & .5 & 51.0 \\
\hline Uttar Kannada & 1 & .5 & 36.2 \\
\hline Total & 208 & 100.0 & & \\
\hline
\end{tabular}

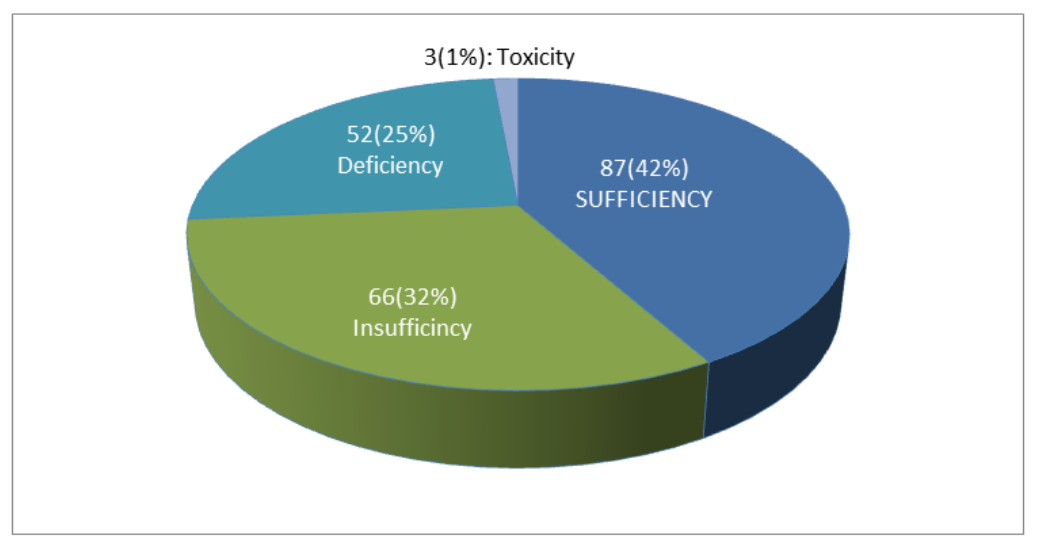

Fig-1: Pie diagram showing participants details based on laboratory reference values

\section{DISCUSSION}

Most of us are neglecting the importance of vitamin D until we come across the deficiency symptoms. Hypovitaminosis is not only causes osteoporosis but also a risk factor for diabetes, cancers of breast, colon, prostate and ovaries. It was found that vitamin D supplementation reduces the risk of heart attacks, rheumatoid arthritis and multiple sclerosis.

Previous study conducted by Sandhiya Selvarajan et al., was found that Vitamin D level was higher in males compared to females. Vitamin D was found to be higher among middle-aged people compared to that of adolescents and those above 50 years of age [12]. One more study conducted by Mohan Kumaratne et al., in Hispanic American obese/overweight adolescents found that around 33.9\% were vitamin D deficient [13].

In a study conducted by Ranadip Chowdhury et al., in young north Indian children, a total of 1000 children were included in the main trial. Of these, 331 $(34.5 \%)$ children were Vitamin D deficient $(<10 \mathrm{ng} / \mathrm{ml})$
[14]. Similarly a study by Venugopal G et al., in Kancheepuram district, Tamil Nadu, fifty nine (13.9\%) of the 424 participants had $25(\mathrm{OH}) \mathrm{D}$ levels below $12 \mathrm{ng} / \mathrm{mL}$ (vitamin D deficient) and 175 (41.3\%) had 25(OH)D levels between 12 to $20 \mathrm{ng} / \mathrm{mL}$ (vitamin $\mathrm{D}$ insufficiency) [15].

Even though many previous studies have revealed that females have low vitamin $\mathrm{D}$ levels than males (which is statistically significant). Our study results are not matching with these studies $[7,8]$.

In our study, we found low levels of vitamin D in females when compared to males but statistically it was not significant $(\mathrm{p}=0.512)$. The intergroup comparison of vitamin $\mathrm{D}$ levels of individuals from different locations didn't show any statistical significance ( $f=1.33 \& p=0.191$ ). Similarly, there is no statistical significant difference in the vitamin D levels of different age groups.

The main limitation of this study is that we did not exclude patients who are on vitamin D 
supplementation and who are suffering from thyroid disorders which might have affected the results. However, in future efforts will be made to consider these limitations while continuing this study.

\section{REFERENCES}

1. Weaver, C. M. (2007). Vitamin D, calcium homeostasis, and skeleton accretion in children. Journal of Bone and Mineral Research, 22(2):4549.

2. Chakrabarty, S., Wang, H., Canaff, L., Hendy, G. N., Appelman, H., \& Varani, J. (2005). Calcium sensing receptor in human colon carcinoma: interaction with $\mathrm{Ca} 2+$ and 1, 25-dihydroxyvitamin D3. Cancer research, 65(2), 493-498.

3. Holick, M. F. (2007). Vitamin D deficiency. New England Journal of Medicine, 357(3), 266-281.

4. Lopez-Molina, M., Santillan, C., Murillo, M., Valls, A., Bosch, L., Bel, J., \& Granada, M. L. (2018). Measured free 25-hydroxyvitamin D in healthy children and relationship to total 25hydroxyvitamin D, calculated free 25hydroxyvitamin $\mathrm{D}$ and vitamin $\mathrm{D}$ binding protein. Clinical biochemistry, 61, 23-27.

5. Garg, M., Lubel, J. S., Sparrow, M. P., Holt, S. G., \& Gibson, P. R. (2012). vitamin D and inflammatory bowel disease-established concepts and future directions. Alimentary pharmacology \& therapeutics, 36(4), 324-344.

6. Jones, G. (2008). Pharmacokinetics of vitamin D toxicity. The American journal of clinical nutrition, 88(2), 582S-586S.

7. Holick, M. F., \& Chen, T. C. (2008). Vitamin D deficiency: a worldwide problem with health consequences. The American journal of clinical nutrition, 87(4), 1080S-1086S.

8. Al-Horani, H., Abu Dayyih, W., Mallah, E., Hamad, M., Mima, M., Awad, R., \& Arafat, T.
(2016). Nationality, gender, age, and body mass index influences on vitamin $\mathrm{D}$ concentration among elderly patients and young Iraqi and Jordanian in Jordan. Biochemistry research international, 2016;1-8.

9. Lips, P. (2001). Vitamin D deficiency and secondary hyperparathyroidism in the elderly: Consequences for bone loss and fractures and therapeutic implications. Endocr Rev; 22:477-501.

10. Heaney, R. P. (2003). Vitamin D depletion and effective calcium absorption. Journal Bone Miner Research, 18:1342.

11. Aparna, P., Muthathal, S., Nongkynrih, B., \& Gupta, S. K. (2018). Vitamin D deficiency in India. Journal of family medicine and primary care, 7(2):324.

12. Selvarajan, S., Gunaseelan, V., Anandabaskar, N., Xavier, A. S., Srinivasamurthy, S., Kamalanathan, S. K., \& Sahoo, J. P. (2017). Systematic review on vitamin D level in apparently healthy Indian population and analysis of its associated factors. Indian journal of endocrinology and metabolism, 21(5), 765.

13. Kumaratne, M., Early, G., \& Cisneros, J. (2017). Vitamin D deficiency and association with Body Mass Index and lipid levels in hispanic american adolescents. Global pediatric health, 4 , $2333794 X 17744141$.

14. Chowdhury, R., Taneja, S., Bhandari, N., Sinha, B., Upadhyay, R. P., Bhan, M. K., \& Strand, T. A. (2017). Vitamin-D deficiency predicts infections in young north Indian children: A secondary data analysis. PloS one, 12(3): $\mathrm{e} 0170509$.

15. Mechenro, J., Venugopal, G., Kumar, M. B., Balakrishnan, D., \& Ramakrishna, B. S. (2018). Vitamin D status in Kancheepuram District, Tamil Nadu, India. BMC public health, 18(1), 1345. 